\title{
Navegar é preciso: avaliação de impactos do uso da internet na relação médico-paciente
}

\author{
Sailing is necessary: evaluation of the impacts of internet \\ access on the doctor-patient relationship
}

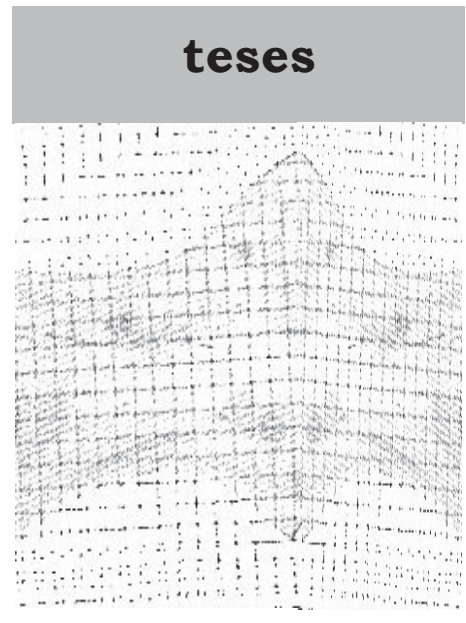

Trata-se de pesquisa com abordagem qualiquantitativa com objetivo de: verificar se indivíduos que acessam a internet a utilizam para consultar informações sobre saúde $e$ doenças; se o paciente, acessando a internet, muda sua atitude de paciente e se verifica mais ativo e mais participante do processo de decisão sobre sua saúde; e se, do ponto de vista do paciente, houve mudança na atitude do profissional médico frente ao maior uso da internet por parte desse paciente.

Como procedimento metodológico empregou-se a técnica do Discurso do Sujeito Coletivo - DSC, que possibilita a identificação $e$ a construção de sujeitos e discursos coletivos distintos, por meio da análise de material individual e da extração das idéias centrais, compondo-se, com o conteúdo das idéias centrais semelhantes, discursos-síntese que expressam as representações sociais de uma coletividade. Para a coleta de dados, utilizou-se um questionário on-line, que ficou disponível por três meses na internet.

A análise dos dados indica que a maioria dos entrevistados acessa a internet com freqüência de, pelo menos, uma vez por semana; a utiliza para consultar informações sobre saúde e doença, relacionadas a casos vivenciados por eles ou por aqueles que os afetam diretamente (familiares) e após alguma consulta médica, para verificar, entender ou complementar as informações oferecidas por seus médicos. Parte significativa dos sujeitos consideram que as informações acessadas na internet sobre saúde e doenças são úteis; utilizam-se dessas informações para conversar com seus médicos em consultas posteriores e demonstram mudança de atitude, em termos de uma postura mais participativa no processo de decisão sobre sua saúde.

A diversidade de discursos coletivos distintos resultantes do estudo, analisados $e$ organizados em tipos e escalas, auxilia na compreensão de questões, tais como: tipo de participação do paciente durante a consulta médica, grau de autonomia do paciente, tipos de interação entre médico e paciente, e tipos de reação produzidas pelos profissionais médicos durante tal processo.

$$
\begin{array}{r}
\text { Wilma Madeira } \\
\text { Dissertação (Mestrado), } 2006 \\
\text { Faculdade de Saúde Pública, } \\
\text { Universidade de São Paulo, São Paulo. } \\
\text { <wilmams@usp.br> }
\end{array}
$$

Texto completo: http://www.teses.usp.br/teses/disponiveis/6/6135/ tde-30102006-103313/

PALAVRAS-CHAVE: relações médico-paciente. internet. comunicação.

KEY WORDS: physician patient-relations. internet. communication.

PALABRAS CLAVE: relaciones médico-paciente. internet. comunicación. 


\title{
A violência por parceiro íntimo (VPI) durante a gestação
}

\author{
Violence and pregnancy: study among public health care users \\ in Grande São Paulo
}

A violência por parceiro íntimo (VPI) durante a gestação tem sido considerada importante problema de saúde pública, pela sua alta magnitude e impacto na morbidade $e$ mortalidade materna $e$ infantil. Neste trabalho pretendeu-se: a) estimar a prevalência da VPI na gestação e verificar sua associação com fatores sociodemográficos, de saúde reprodutiva, sexual e mental entre usuárias de serviços públicos de saúde da Grande São Paulo; b) conhecer se a ocorrência da VPI na gestação está associada à recorrência e gravidade da VPI na vida da usuária; c) identificar aspectos da vulnerabilidade individual e contextual relacionados à violência.

Os procedimentos metodológicos incluíram: a) entrevistas estruturadas (questionário) com 1.922 usuárias, entre 15 e 49 anos, em 14 serviços públicos de saúde; b) três grupos focais com gestantes, e c) 4 entrevistas em profundidade com mulheres que sofreram VPI na gestação.

$\mathrm{Na}$ análise quantitativa dos dados observou-se que $20 \%$ das gestantes investigadas (IC $95 \%$ 18,2 a 21,8) referem algum episódio de VPI na gestação. Em análise multivariada, foi contrastada a variável dependente "violência por parceiro íntimo durante a gestação", dicotômica (presença ou ausência), contra 14 variáveis que, em análise univariada, estiveram associadas a VPI na gestação. Observou-se que: sofrer violência psicológica por familiar (ORa 1,54; IC: 1,10 a 2,14); sofrer violência física por familiar (ORa 1,98: IC: 1,30 a 3,03); ter mais de três gestações (ORa 3,44:
IC 2,39 a 4,96); início da vida sexual antes dos 15 anos (ORa 1,98: IC: 1,37 a 2,85) e a presença de Transtorno Mental Comum (ORa 2,16: IC 1,68 a 2,77) são fatores associados à VPI na gestação, controlados pela escolaridade da usuária.

Em uma subamostra composta pelas usuárias que referiram VPI alguma vez na vida $(n=1165)$, realizou-se análise univariada e observou-se que a VPI na gestação está associada a: sofrer VPI psicológica grave ao longo da vida ( $R P=2,69$ : IC: 1,86 a 3,91); sofrer VPI física grave ao longo da vida ( $R P=$ 1,96: IC 1,61 a 2,40); sofrer VPI psicológica "muitas vezes" ( $R P=2,94:$ IC: 2,02 a 4,27); sofrer violência física "muitas vezes" ( $\mathrm{RP}=$ 2,2; IC 1,8 a 2,70). Constata-se, portanto, que as usuárias que referem VPI na gestação apresentam padrão mais grave e freqüente de VPI na vida.

No estudo qualitativo, foram caracterizadas as condições de vulnerabilidade à VPI na gestação, segundo aspectos da trajetória social da usuária, da interação da trajetória dela e do parceiro, e do contexto social. Constatou-se que, no nível da trajetória social, o fenômeno relaciona-se com desproteção na família de origem, com a experiência de desenraizamento social e com projeto de vida de reinserção social por meio do casamento. No âmbito da interação das trajetórias, a dúvida quanto à paternidade, a gravidez indesejada, as mudanças no corpo $e$ na libido da mulher, $e$ a percepção da gestação como momento de dependência feminina são fatores que tornam mulheres vulneráveis à VPI na gestação. E, por fim, no 
âmbito do contexto social, a concepção de que a vida reprodutiva $e$ as medidas contraceptivas são atribuições femininas também favorece a ocorrência de VPI na gestação.

A alta prevalência de VPI na gestação e sua associação com agravos à saúde mental sugerem que esta questão deve ser vista como importante problema de saúde pública. Além disto, o estudo demonstra que a VPI na gestação está relacionada a padrão grave de violência na vida e sinaliza a importância de intervenções nesse período.

Julia Garcia Durand Dissertação (Mestrado), 2006 Departamento de Medicina Preventiva, Faculdade de Medicina, Universidade de São Paulo, São Paulo. $<$ juliadurand@ hotmail.com>

Texto completo http://www.teses.usp.br/teses/disponiveis/5/5137/ tde-24052006-155058/

PALAVRAS-CHAVE: maus tratos conjugais. gravidez. violência doméstica. fatores socioeconômicos.

KEY WORDS: spouse abuse. pregnancy. domestic violence. socioeconomic factors.

PALABRAS CLAVE: maltrato conjugal. embarazo. violencia doméstica. factores socioeconomicos.

\section{Águas da Pedagogia da Implicação: intercessões da educação para políticas públicas de saúde}

\author{
Waters of pedagogy of \\ implication: intercessions of the \\ education for public health policies
}

A dissertação reporta a construção $e$ apresenta a defesa de uma pedagogia da implicação, proposta que configura o ensinoaprendizagem como a gestão de processos de mudança de si e dos entornos, detectada na realização de cursos de aperfeiçoamento $e$ especialização componentes de um projeto político de saúde. A formação aparece como eixo estrutural de uma política de saúde mental inovadora $e$ ousada. A organização $e$ os métodos de educação escolhidos tornaram a ação de formação muito mais ousada que a habilitação de pessoas para uma prática técnica, política ou administrativa diferente; funcionaram como agregadores de coletivos, disparadores de desejo e ativadores de processos de mudança, mobilizando atos $e$ estratégias políticas no interesse do acolhimento de pessoas em projetos de vida e de presente, da democracia, cidadania $e$ autoria.

Para o percurso da escrita, na procura de uma teoria, foi utilizada a imagem das águas $e$ das navegações. Os grandes itinerários estão nos cursos de saúde mental coletiva e no "curso" da saúde mental coletiva em sua história, geografia e sentidos nas políticas públicas de saúde; no "curso" da educação permanente em saúde, e no "curso" dos movimentos sociais que preenchem uma educação da cidadania. Esses "cursos" produziram a "correnteza" da saúde mental coletiva, modos coletivos de gestão e de 
atenção em saúde, processos de educação permanente em saúde e o Fórum Gaúcho de Saúde Mental.

As âncoras de uma Pedagogia da Implicação são categorias analisadoras, conceitos caixa-de-ferramenta e o encontro com a invenção/criação de dispositivos operadores singulares, tendo em vista propiciar um poder-aprender-saber-fazer no cotidiano dos percursos, bem como na (re)definição das rotas. A saúde mental coletiva não existia antes desse percurso, ela se fez em percurso de desejo molhado pelas vidas singulares de trabalhadores, gestores, participantes e seus familiares e formadores implicados com a despsiquiatrização da loucura e com a gestão de processos de mudança de si e dos entornos.
O trabalho emite uma Carta Náutica ou uma carta-leitura das Intercessões da Educação para uma Política Pública de Saúde, com os traçados entrelaçados por matriciamentos e transversalizações, com pontos de sustentação, vazios de incompletude, produtora de devir e com outras vontades de potência: convite à implicação. Uma carta náutica das transformações da Nau da Liberdade Saúde Mental Coletiva, navegando nas águas da Pedagogia da Implicação.

Sandra Maria Sales Fagundes Dissertação (Mestrado), 2006, Programa de Pós-Graduação em Educação, Faculdade de Educação, Universidade Federal do Rio Grande do Sul, Porto Alegre. <sandrafagundes@cpovo.net> 


\title{
Estudo sobre diretrizes e práticas de atenção à saúde mental: um enfoque nos procedimentos de avaliação inicial $e$ planejamento terapêutico em serviços substitutivos de Botucatu
}

\author{
Guidelines and mental health practices study: a focus on initial evaluation \\ procedures and therapeutic planning in Botucatu substitute health services
}

O presente trabalho revê a organização do sistema de saúde brasileiro ao longo da história, com destaque para o desenvolvimento da assistência à saúde mental dentro desse processo. São enfocados os movimentos sociais em busca de mudanças, como o Movimento Sanitário e a Reforma Psiquiátrica no país, assim como as políticas públicas que marcaram significativamente a situação atual.

Além disso, apresenta questões relativas às articulações existentes na estrutura política do país que determinaram, de acordo com o modo de produção adotado, o olhar para a doença e para o doente, resultando que as ações no campo da saúde estivessem ligadas $e$ voltadas principalmente à condição produtiva dos indivíduos.

Apresentam-se, ainda, algumas considerações sobre o contexto da assistência à saúde mental contemporânea e seu processo de transformação a partir de análise de documentos e revisão bibliográfica não exaustiva, com a proposta de compreender aspectos preconizados pela Organização Mundial da Saúde e Legislação Brasileira para o cuidado em saúde mental, apontando influências internacionais. A partir dessa breve compreensão, entende-se que informações sobre os pressupostos para o tratamento são subsídios importantes para a construção da luta pela saúde mental $e$ cidadania.

Considera-se, neste trabalho, que a reestruturação da prática cotidiana dos serviços de saúde mental é condição essencial para a transformação proposta para o modelo assistencial em nosso país. O presente estudo questionou profissionais de equipes de serviços substitutivos de saúde mental do município de Botucatu, em relação aos sentidos atribuídos por eles aos procedimentos de avaliação inicial $e$ planejamento terapêutico, como constituintes do tratamento oferecido nestes serviços. Para tanto, utilizou-se a perspectiva das práticas discursivas e produção de sentidos no cotidiano proposta por Spink. Observaram-se diferenças conceituais $e$ paradoxos que explicitam o período de transição pelo qual o modelo está passando. Tais observações mostram a necessidade de transformar não apenas a norma legal, mas também os conteúdos implícitos nas ações diárias por parte dos profissionais, possibilitando a ressignificação das relações sociais que ali se estabelecem.

Helen Isabel de Freitas Dissertação (Mestrado), 2006 Programa de Pós-Graduação em Saúde Pública, Faculdade de Medicina de Botucatu, Universidade Estadual Paulista, Botucatu. <hifreitas@yahoo.com.br>

PALAVRAS-CHAVE: políticas de saúde mental. reforma psiquiátrica. avaliação inicial. planejamento terapêutico. práticas discursivas.

KEY-WORDS: mental health policy, psychiatric reform. first assessment. therapeutic project. discursive practices.

PALABRAS CLAVE: políticas de salud mental. reforma psiquiátrica. valuación inicial. proyecto terapéutico. prácticas discursivas. 


\title{
A atenção em saúde mental em municípios de pequeno $e$ médio portes: ressonâncias da reforma psiquiátrica
}

\author{
Psychosocial attention in small and medium-sized towns: resonances of \\ the psychiatric reform
}

Este estudo busca conhecer as ressonâncias da reforma psiquiátrica em municípios de pequeno e médio portes, situados na região oeste do Estado de São Paulo. Com base na análise da política nacional de saúde mental formulada nos últimos anos e nas experiências desenvolvidas, após 1987, em São Paulo (capital), Santos e Campinas, procura-se: compreender como o Sistema único de Saúde (SUS) tem contribuído para o avanço da reforma psiquiátrica nos municípios; verificar como a assistência oferecida, nesses municípios, está viabilizando os princípios da reforma psiquiátrica e a melhora das condições de vida dos usuários, bem como pesquisar o papel dos trabalhadores e dos gestores na construção de novas práticas de cuidado em saúde mental. A análise das práticas discursivas encontradas nos textos, documentos, bem como de entrevistas semiestruturadas com gestores, trabalhadores, usuários dos serviços de saúde mental apontam que os vários segmentos sociais envolvidos na saúde mental conhecem os princípios e propostas da reforma psiquiátrica. No entanto, as gestões municipais não assumem integralmente as propostas do Ministério da Saúde para a área, sob a alegação de falta de recursos financeiros para a contrapartida exigida. No município menor, o serviço de saúde mental se organiza no centro de saúde, oferecendo uma assistência mais integral aos usuários, com pouca incidência de encaminhamentos desencontrados. No município maior, realizam-se mais ações de reinserção psicossocial, tendo um Centro de Atenção
Psicossocial em funcionamento. Os usuários e seus familiares têm gradativamente assumido as novas propostas de intervenção, mas os mecanismos de participação e organização popular ainda são incipientes na saúde mental. Finalmente, deve-se destacar que, para uma efetiva consolidação das propostas atuais da reforma psiquiátrica, é necessário, entre outras ações: maior compromisso dos gestores com a atenção em saúde mental; maior investimento nas equipes multiprofissionais; estímulo à organização $e$ participação dos usuários e familiares, $e$ integralidade dos dispositivos de saúde, de assistência social e de cultura existentes nas cidades, com objetivo de construir uma rede de cuidado e reinserção social.

Cristina Amélia Luzio
Tese (Doutorado), 2003.
Programa de Pós-Graduação em Saúde Coletiva,
Faculdade de Ciências Médicas,
Universidade Estadual de Campinas.
<caluzio@assis.unesp.br>

PALAVRAS-CHAVE: reforma psiquiátrica. atenção psicossocial. saúde mental. saúde coletiva.

KEY-WORDS: psychiatric reform. psychosocial attention. mental health. collective health.

PALABRAS CLAVE: reforma psiquiátrica. atención psicosocial. salud mental. salud colectiva. 